\title{
The spatial-temporal transfer of scientometrics research topics based on citation analysis
}

\author{
Jianhua Hou ${ }^{1}$ and Xiucai Yang ${ }^{2}$ \\ ${ }^{1}$ School of Information Management, \\ Sun Yat-Sen University, Waihuan East Road, Panyu District, \\ Guangzhou, Guangdong 510006, CHINA \\ ${ }^{2}$ College of Economics and Management, \\ Dalian University, Dalian Economic Technological Development Zone, \\ Dalian 116622, CHINA \\ e-mail: houjh5@mail.sysu.edu.cn (corresponding author); yangsir7510@gmail.com
}

\begin{abstract}
In this study, the spatial-temporal transfer of research topics in the field of scientometrics was analysed through citation analysis and information visualization tools such as CiteSpace and Google Fusion Tables software. We collected 12,839 articles, including 214,748 references, about citation analysis in Science Citation Index-Expanded (SCI-E) and Social Science Citation Index (SSCI) databases for the period of 1971 to July 2016 as the data source. We obtained the following findings: The transfer of central research topics in the field of scientometrics is accelerating. There have been three milestones: the middle of the 1990s, 2005, and 2010. The number of central research topics has also changed from one between 1971 and 1993 to two after 1994 and three after 2008. At the same time, the geographical centres of scientometrics research showed a general shift from the US and Britain to Italy, the Netherlands, Belgium, Spain, and China. At present, the countries that are centres of research include the Netherlands, US, Belgium, China, Spain, and Italy. There is a close positive correlation between the transfer of the central research topic and the transformation of the country to a centre of research. The countries acting as centres of research enjoy not only a high output of literature, but also a great academic influence. Both the theoretical and practical implications of the results are discussed.
\end{abstract}

Keywords: Scientometrics; Transfer of research centres; Information visualization; Scientific impact; Societal impact.

\section{INTRODUCTION}

Scientometrics considers science as the object of study and explores its characteristics and laws of development through quantitative analysis. The scientific activities it studies include the investment (such as researchers and research funding), output (such as the number of papers and citations), and progress (such as information dissemination and communication network formation). Eugene Garfield established the Science Citation Index (SCl), providing a data basis for scientometrics research. With the improvement of online databases and the rapid development of computer technology since the 1990s, scientific literature data sources including the Web of Science (WoS), Scopus, and Google Scholar have been providing an important basis for analyzing the rapid development of scientometrics. Science mapping based on citation databases and information visualization technology has injected vigour into the development of traditional scientometrics, and has played an important role 
in studies on the evolution of scientific knowledge, research fronts and hotspots, scientific collaboration, new trends of science and technology, and the law of development of science. Meanwhile, the requirement for research performance evaluation and scientific research appraisal from the government, universities, and institutes also stimulated the development of scientometrics. Research on scientometric evaluation indexes, represented by the h-index and journal evaluation index (for example, SNIP [Moed 2010] and SCImago Journal Rank [SJR][González-Pereira, Guerrero-Bote and Moya-Anegón 2010; Guerrero-Bote and MoyaAnegón 2012]), has been greatly developed since 2005. Scientometrics plays an important role in the evaluation and measurement of scientific research, evaluation of scientists (and their institutions), science and technology policy making, and other research areas. In 2010, scientometrics shifted its research orientation from the evaluation of academic influence in the field of science to the evaluation of the influence on all aspects of society with the advent of the web and social networks. This has brought about the possibility of alternatives to citations as ways of measuring impact, such as altmetrics. Altmetrics is currently underdeveloped. However, this impact indicator may rival citations in the future (Mingers and Leydesdorff 2015). In recent years, there has been a rapid increase in scientometric literature, and emerging research trends and front topics have come forth constantly. The institutions and countries engaged in these studies have also changed significantly.

This study conducts an in-depth and comprehensive analysis that is not only a visualization on the evolution of research topics of scientometrics but also a comparative analysis between the central topic of the research and the country as the centre of research. Specifically, it aims to answer the following questions:

(a) What are the Spatial-Temporal transfer characteristics and laws of Scientometrics centres of research?

(b) What is the relationship between the location of scientometrics research centres and their academic influence?

\section{RELATED WORK}

\section{Transfer of the Centre of Scientific Activity}

William Dampier, a British historian of science put forward the idea of "world science centre" in his work A History of Science and its Relations with Philosophy and Religion for the first time (Dampier 1966). In 1954, J.D. Bernard, a British scientist, put forward the idea of "the centre of technological and scientific activity" in his book Science in History for the first time and enumerated the clues for the transfer of centre of technological and scientific activity in history (Bernard 1954). Enlightened by Science in History, Yuasa (1962) discovered the law of transfer of the centre of scientific activities. The centre of scientific activity can be defined as a country whose scientific achievements account for over 25 percent of the total achievements in the world during a particular period. Scientific prosperity means the period in which a country is the world's centre of scientific activity. Zhao and Jiang (1985) also discovered this phenomenon. He pointed out the optimum age for making scientific discoveries through statistical methods, formulated an experiential formula among the number of scientific achievements, number of scientists, and their social ages, and explained the Yuasa Phenomenon to some extent. Liang, Feng and Wu (2000) explored the geographical and chronological characteristics of the shift of centre of scientific activity on the basis of 4087 records retrieved from two chronological tables about the history of science and technology. With the accelerating development of scientific researches and cognitive activities, the boundaries of scientific activity centres have become more blurred. Some countries have even jointly become the world's centre of scientific activity. The 
research topics for the disciplines, the knowledge constituting the complex knowledge system of science, and their geographical distribution are also changing and shifting rapidly. However, few studies have been conducted to explore the law of the transfer of the centre of research activity in a particular field of disciplines and knowledge. This research attempts to discover the law of transfer of research centre of scientometrics through scientometric analyses.

\section{Review of the Development of Scientometrics Research}

Leydesdorff (2015) reviewed the development of scientometrics and pointed out that it is a quantitative discipline, which considers science as a communication system. Although it studies multiple dynamic aspects of the development of science and technology, scientometrics actually centres on the study of citation analysis. In addition, scientometrics studies such aspects as the measurement methods of research quality and impact, citation process, science mapping, science and technology policy, and the application of measuring index in management (Bornmann 2015; Leydesdorff 2015). In 1939, Bernard published the book The Social Function of Science, and became the first person to propose the study of the science of science, laying an important theoretical foundation for scientometrics (Bernard 2010). In the 1950s, Garfield introduced the idea of citation analysis for the first time and established the Science Citation Index (SCI) (1962); Social Sciences Citation Index (SSCI) (1973); and Arts \& Humanities Citation Index (A\&HCl) (1978).

In the 1960s, Price put forward the idea of literature and author network, "invisible college," and "Matthew Effect" in scientific research for the first time. Being the first one to apply quantitative indexes in science and technology policy making, Price is credited as the father of scientometrics (Garfield 2009). In 1973, Small and Marshkova put forward the idea of document co-citation analysis and provided an important method for scientometrics from the perspective of citation analysis (Marshakova 1973; Small 1973). In 1978, the journal Scientometrics was launched by the Hungary Academy of Sciences, marking the establishment of scientometrics as an independent discipline. In the 1990s, scientometrics research experienced great changes and faced many challenges during its rapid development (Leydesdorff 2015).

In recent years, scientometrics has been playing an important role in the evaluation and measurement of research performance. This discipline, as Kuhn stated, is a normal science now, or in other words, it has entered its maturity stage. A scientific revolution of scientometrics took place after 2010 (Bornmann 2012; 2015). Being a principal part of scientometric study, the influence of research currently refers to not only its influence on science, but also the influence on society, including the influence of research on social, cultural, environmental, and economic aspects. The new tools and methods, which play important roles in measuring the societal impact of research, are called altmetrics. This new scientometrics method of evaluating academic influence is also called Scientometrics 2.0 (Priem and Hemminger 2010).

\section{Research on the Evolution of Scientometrics Based on Citation Analysis}

Most studies use data from the journal Scientometrics and employ document co-citation analysis (DCA), author co-citation analysis (ACA), social network analysis, multidimensional analysis, and cluster analysis in drawing the science mapping of scientometrics to show the knowledge structure and evolution of scientometrics during a certain period (Table 1). Schubert (2002) analyzed the knowledge structure of the first 50 volumes of Scientometrics through authorship and co-authorship characteristics, as well as citation and reference patterns. Dutt, Garg and Bali (2003) analyzed the data from the first 50 volumes of 
Scientometrics (between 1978 and 2001) and found that the number of papers produced by the US was decreasing, while those produced by the Netherlands, India, France, and Japan were increasing. Chen et al. (2002) employed information visualization to draw the citation and co-citation patterns of Scientometrics (1981-2001) and to show the evolution of scientometrics. Schoepflin and Glänzel (2001) classified the literature published by Scientometrics in 1980,1989, and 1997 into six categories, and suggested that this field is heterogeneous and that each sub-discipline has distinctive characteristics. Ravikumar, Agrahari and Singh (2015) studied 959 articles published by Scientometrics between 2005 and 2010, employing text mining and co-words analysis to explore the intellectual structure of scientometrics in this period as well as the trends and patterns of scientometrics. Using the volumes of Scientometrics published between 1978 and 2011, Wang, Qiu and Yu (2012) made a cross-citation analysis between highly productive authors and highly cited authors and revealed the knowledge communication and disciplinary structure in scientometrics.

Table 1: Related Research on the Evolution of Scientometrics

\begin{tabular}{|c|c|c|c|c|}
\hline Study & Period & Data & Method & Analysis \\
\hline $\begin{array}{l}\text { Schoepflin } \\
\text { and Glänzel } \\
\text { (2001) }\end{array}$ & $\begin{array}{c}1980 \\
1989,1997\end{array}$ & Scientometrics & $\begin{array}{l}\text { Calculate the citation } \\
\text { indicators }\end{array}$ & $\begin{array}{l}\text { Heterogeneous, sub- } \\
\text { discipline has its own } \\
\text { characteristics. }\end{array}$ \\
\hline $\begin{array}{l}\text { Chen et al. } \\
(2002)\end{array}$ & 1981-2001 & Scientometrics & $\begin{array}{l}\text { Information visualization } \\
\text { and animation techniques }\end{array}$ & $\begin{array}{l}\text { Evolutionary and } \\
\text { historical of } \\
\text { scientometrics }\end{array}$ \\
\hline $\begin{array}{l}\text { Ravikumar, } \\
\text { Agrahari } \\
\text { and Singh } \\
\text { (2015) }\end{array}$ & $2005-2010$ & Scientometrics & $\begin{array}{l}\text { Text mining and co-word } \\
\text { analysis }\end{array}$ & $\begin{array}{l}\text { Trends and patterns } \\
\text { of scientometrics }\end{array}$ \\
\hline $\begin{array}{l}\text { Wang, Qiu } \\
\text { and Yu } \\
(2012)\end{array}$ & $1978-2011$ & Scientometrics & Cross-citation analysis & $\begin{array}{l}\text { Knowledge } \\
\text { communication and } \\
\text { disciplinary structure } \\
\text { in Scientometrics }\end{array}$ \\
\hline $\begin{array}{l}\text { Hou, } \\
\text { Kretschmer } \\
\text { and Liu } \\
\text { (2008) }\end{array}$ & $1978-2004$ & Scientometrics & ACA, SNA & $\begin{array}{l}\text { Scientific } \\
\text { collaboration } \\
\text { networks at } \\
\text { individuals level }\end{array}$ \\
\hline $\begin{array}{l}\text { Chen, } \\
\text { Borner and } \\
\text { Fang (2013) }\end{array}$ & $1978-2010$ & Scientometrics & Co-occurrence analysis & $\begin{array}{l}\text { Scientific } \\
\text { collaboration } \\
\text { networks at micro, } \\
\text { meso and macro level }\end{array}$ \\
\hline $\begin{array}{l}\text { Zhao and } \\
\text { Zhao (2016) }\end{array}$ & $1987-2015$ & $\begin{array}{l}\text { Scientometrics, } \\
\text { JASIST, Journal } \\
\text { of Informetrics }\end{array}$ & $\begin{array}{l}\text { Social network analysis, } \\
\text { Cluster analysis }\end{array}$ & $\begin{array}{l}\text { Scientific } \\
\text { collaboration } \\
\text { networks at micro, } \\
\text { meso and macro level }\end{array}$ \\
\hline
\end{tabular}

In addition, some researchers analyzed scientometrics through the evolution of cooperative network. Hou, Kretschmer and Liu (2008) drew a knowledge map of all the literature types of the articles published in Scientometrics between 1978 and 2004. They used social network analysis and revealed the cooperative network structure as well as the main cooperative 
field, subfield, and collaborating centre of scientometrics at the micro level. Chen, Borner and Fang (2013) analyzed the cooperative network of scientometrics from the perspectives of author (micro), institution (meso), and countries (macro) based on the literature published by Scientometrics between 1978 to 2010, and analyzed the influence of each level on the others. Zhao and Zhao (2016) revolutionized the selection of literature and chose the data published by Scientometrics, Journal of the Association for Information Science and Technology (JASIST), and Journal of Informetrics in 29 years. They also employed social network analysis and conducted visualized analyses of the evolution of the cooperative network of scientometrics during the three periods, 1987-1996, 1997-2006, and 20072015.

The studies by Chen et al. (2002), Chen, Borner and Fang (2013), Hou, Kretschmer and Liu (2008), Ravikumar, Agrahari and Singh (2015), Schoepflin and Glänzel (2001), and Wang, Qiu and $\mathrm{Yu}$ (2012), all used the publications in Scientometrics as their data sources. While being a mainstream journal in the field, it could still miss a large number of papers published in other journals in the field of scientometrics, which is a point overlooked in data selection. Zhao and Zhao (2016), on the other hand, used the literature published in Scientometrics, JASIST, and Journal of Informetrics for data analysis, which to a certain extent improves the scope of the data source and provides a more accurate analysis of scientometrics. However, according to the existing studies, (a) most studies analyze the evolution of scientometrics in a specific period, while few tracked the overall evolution path over a long period. In particular, few studies analyzed the long-term evolution of the central research topics; (b) most analyses on the evolution of scientometrics are qualitative with a certain amount of subjectivity. Based on the literature, some research conducted qualitative analyses on the overall evolution of scientometrics, which can be divided into several periods (1987-1996, 1997-2006, and 2007-2015). This division of evolution is subjective to some extent; (c) most studies conduct citation analysis on the evolution of scientometrics based on the literature data from Scientometrics. Although Scientometrics is the most representative journal in this field, it cannot represent scientometric studies entirely due to the evolution and expansion of professional journals in scientometrics and the rapid development of bibliometrics, informetrics and webometrics, as well as altmetrics. Therefore, data from journals other than Scientometrics should be analyzed. We take a two-step method to identify the central research topics of the scientometrics field. Firstly, we identify the core journals (top $25 \%$ in co-citation frequencies) of the scientometrics field through journal co-citation analysis (JCA) based on the research published in the journal Scientometrics. Then, we identify the central research topics (exceeding $25 \%$ of the total research topics for that year) between 1971 and 2016 through the scientometric analysis method based on the selected journals data identified in the first step. It then extracts the distribution information of the institutions and countries that produced this literature, focusing on the temporal and spatial transformation of the scientometrics central research, to reveal the relationship between changes in the central research topic and the country as centre of research.

\section{MATERIALS AND METHOD}

Scientometrics has become the flagship journal in scientometrics after 40 years of development since its establishment in 1978 (Chen et al. 2002). This journal publishes articles mainly in the field of scientometrics and informetrics (Bar-llan 2008). Scientometrics plays an important role not only in scientometrics, but also in library and information science (Wang, Qiu and Yu 2012). Its development shows the structure and forward trend of scientometric studies. However, with the development of scientometrics, more journals 
have begun to publish literature about scientometrics research results, especially literature in informetrics, bibliometrics, and webometrics. Due to their similar research objectives and methods, bibliometrics, scientometrics, informetrics, and webometrics are seen as a unified research area, namely, iMetrics, the range of which covers Scientometrics, Journal of Informetrics, and a part of JASIST (the other part of JASIST mainly includes literature about information science) (Milojevic' et al. 2013). Therefore, Scientometrics can no longer be considered to cover all the literature about scientometrics studies, since other related journals also contain significant amounts of scientometrics literature.

In order to cover a comprehensive literature on scientometrics studies and less literature on other fields, this study chose the data in the following ways: (a) use Scientometrics, the authoritative journal named after the discipline itself, as the data source; (b) employ the retrieval platform, Web of Science, to retrieve and download all the articles and criticisms in every issue of Scientometrics published from 1978 to 2016; (c) conduct journal co-citation analysis and rank the result according to their co-citation frequency from the highest to the lowest - taking 25 percent as the criterion for core data according to the Yuasa (1962) phenomenon, and choose journals whose accumulated co-citation frequency ranks among the top $25 \%$ in the total citation frequency as the data source journals. Accordingly, four important journals were chosen: Scientometrics (with accumulated co-citation frequency of $12.03 \%$ of the total co-citation frequency), JASIS/JASIST (with accumulated co-citation frequency of $8.35 \%$ ), Research Policy (with accumulated co-citation frequency of $4.11 \%$ ), and Journal of Informetrics (with accumulated co-citation frequency of $2.75 \%$ ). The total output of literature in these four journals from their establishment to 2016 is shown in Table 2 (Science and Nature are not included as comprehensive journals in this research). Except for Research Policy, the other three journals are in iMetrics. Studies about the application of research evaluation and co-citation analysis in policy science emerged in the wake of the establishment of the discipline of scientometrics, followed by the establishment of the special journal Research Policy relating to policy studies (Leydesdorff 2015; Milojevic' Leydesdorff 2013).

Table 2: List of the 4 Core Journals recorded by WOS (all Literature Types are included)

\begin{tabular}{ccc}
\hline \hline Journal Title & Period & Total Output \\
\hline Scientometrics & $1978-2016$ & 4747 \\
JASIS/JASIST & $1971-2016$ & 6125 \\
Research Policy & $1974-2016$ & 3063 \\
Journal of Informetrics & $2007-2016$ & 698 \\
\hline \hline
\end{tabular}

Note. JASIS/JASIST, which was launched in 1950, was not recorded in the database until 1970. It was renamed "Journal of the American Society for Information Science" between 1970 and 2000, "Journal of the American Society for Information Science and Technology" in 2001, and "Journal of the Association for Information Science and Technology" in 2014.

This study conducted a year by year document co-citation analysis (DCA) and cluster analysis of the scientometrics literature between 1971 and 2016. The main software used were CiteSpace and Google Fusion Tables. For the analysis of research topics, CiteSpace (Chen 2006; 2017; Chen, Ibekwe-SanJuan and Hou 2010) was applied to examine the year-by-year co-citation pattern of the literature between 1971 and 2016. This program uses a spectral clustering algorithm to perform cluster analysis on the keywords of the co-citation networks previously obtained, in which a similarity matrix $\mathrm{W}$ is first constructed for the collection of 
objects, and the first " $\mathrm{K}$ " eigenvalues and eigenvectors of this similarity matrix or Laplacian matrix are calculated to build an eigenvector space. $\mathrm{K}$-means clustering algorithm is used in the last step to cluster the eigenvectors in this space. The cluster size is determined by the number of nodes present in each cluster. Research topics with cluster size occupying more than $25 \%$ of the total for that year are designated as the yearly central topic to explore the year-by-year scientometrics variation.

For the selection of geographical research centres and central research institutes, the citing papers of the node in the cluster for the central research topics are analyzed to obtain the countries and institutes of all the first authors, which are ranked from high to low according to their frequency of appearance. The top five countries and institutes are chosen as the central research countries and institutes. For the geographical distribution of research topics, Google Fusion Tables (https://www.google.com/ fusiontables/data?Dsrcid=implicit) was used for the year-by-year visualization (Bradley, Roberts and Dennison 2011; Signore 2016).

\section{RESULTS}

After filtering and removing duplicates from the 14,633 papers in Table 2, a total of 12,839 papers containing 214,748 citations were selected for the period 1971-2016. According to the trend in the quantity of literature in these four journals from 1971 to 2016 (Figure 1), three periods are evident: Period I, 1971-1994 (number of published articles at an average of 200 per year), Period II, 1995-2005 (number of published articles at an average of 200 to 400 per year), and Period III, 2006-2016 (number of published articles exceeding 400 and continuing to rise).

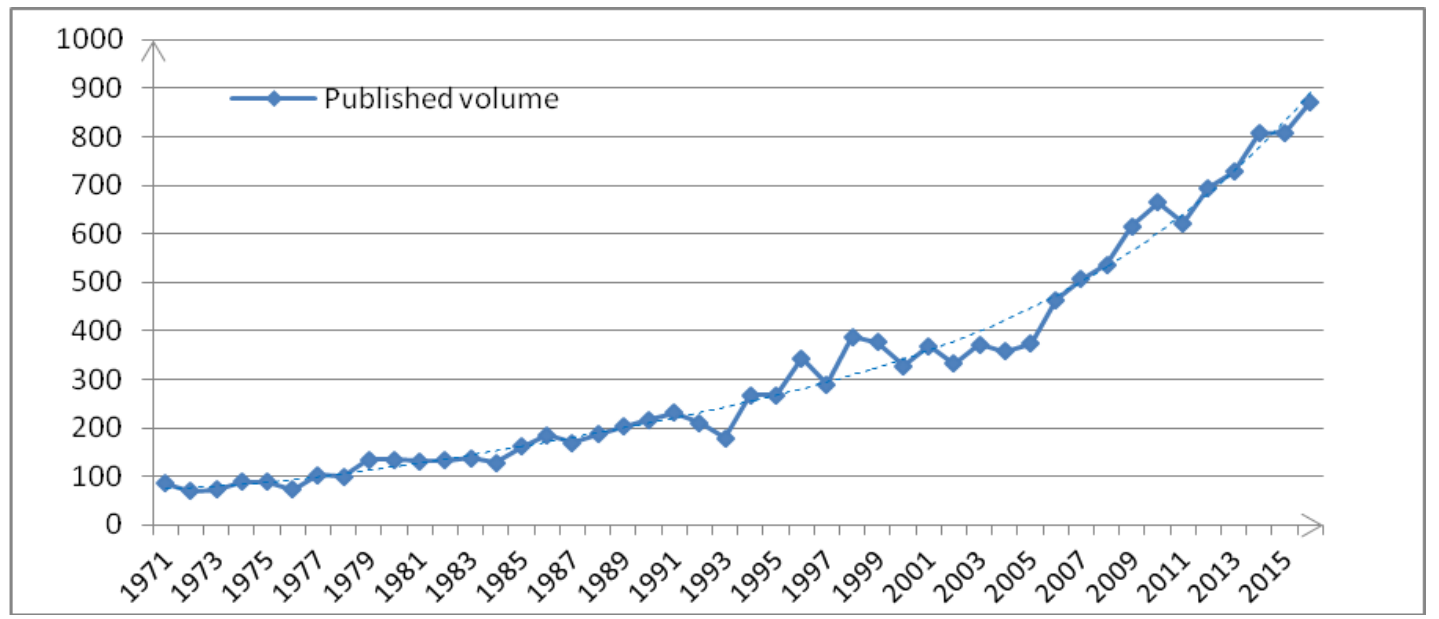

Figure 1: Total Number of Articles Published between 1971 and 2016 (4 selected journals)

\section{The Evolution of Central Research Topics}

The cluster results of each year are arranged according to the cluster size (including the number of the nodes of citations) from the highest to the lowest. According to the criterion mentioned above, the top $25 \%$ clusters of research topics in one year are the central research topics of scientometrics for that year (Table 3-5). Among the three periods of scientometrics (in terms of the journal literature output mentioned above), the first period (1971-1994) reveals a relatively low output of literature (less than 200 articles per year). 
Therefore, this study will focus on the analyses of the transfer of scientometrics research centres in the second (1995-2005) and third period (2006-2016).

Scientometrics is a methodological and applied discipline (Wouters and Leydesdorff 1994). The methodological aspect is manifested in such keywords as information retrieval, citation analysis, webometrics, patentometrics, h-index, bibliometric mapping, and twitter index. The applied aspect is manifested in keywords such as technological innovation, technology policy, research performance, scientific combination, and scientific evaluation. From the 1970s to 1994 (Period I), the central research topics were centered on technology and methods used for information retrieval and on bibliometrics such as Lotka's Law and scientific journal research. In 1994, information retrieval constituted 21 percent of the central research topics for that year (Table 3 ).

Table 3: First-stage Evolution in Central Research Topics (Period I: 1971-1994)

\begin{tabular}{cccccc}
\hline \hline Year & $\begin{array}{c}\text { Cluster } \\
\text { Identifier(Size) }\end{array}$ & $\begin{array}{c}\text { Proportion } \\
\text { in total size }\end{array}$ & Year & $\begin{array}{c}\text { Cluster } \\
\text { Identifier(Size) }\end{array}$ & $\begin{array}{c}\text { Proportion } \\
\text { in total size }\end{array}$ \\
\hline Lotka's Law & $13 \%$ & & $\begin{array}{l}\text { Information } \\
\text { retrieval }\end{array}$ & $21 \%$ \\
$1971-1993$ & Scientific journal & $11 \%$ & 1994 & Basic research & $15 \%$ \\
& Information retrieval & $10 \%$ & & &
\end{tabular}

$\overline{\text { Note: Proportion in total size means nodes of cited papers (proportion of total size is from citations, }}$ and not the number of papers)

From 1995 to 2005 (Period II), scientometrics studies underwent great changes (Leydesdorff 2015). With the rapid development of information science and computer technology, especially the improvement of scientific databases, new methods of scientometrics research, including science mapping and information visualization, were extensively used and spread, providing the government and enterprises with important technological support for technological forecasting and management, science and technology policy-making, as well as discipline development plan (Table 4).

To be specific, studies between 1995 and 1996 were centered on technological innovation. The topics of technological innovation and revolution accounted for over 20 percent of the research topics that year. During 1997-1998, studies centered on technology and methods, with information retrieval and bibliometrics dividing the research topics evenly. Between 1999 and 2000, the research topics were focused on the applications related to technology policy. In 2000, studies on technology policy exceeded 20 percent of the total. During 20012004 , the central research topics centered on webometric studies. Each of the web search, web link, and web impact factors accounted for over $1 / 3$ of the total research topics. Citation analysis and information retrieval remained as the basis of webometric studies. Between 2005 and 2006, the research focus turned to enterprise management application, the pace of innovation, research performance, and corporate value. The patent citation research first emerged in 2007 and patent metrics became the central topic in scientometric studies.

After 2006 (Period III), scientometrics entered a period of rapid development. Great changes took place in this period. First, science mapping and information visualization technology underwent sustained and rapid development and remained as the core technologies in 
scientometrics. Second, the studies on scientometric indicators represented by $\mathrm{h}$-index achieved leapfrog development. The government's promotion of the evaluation and assessment of research performance greatly impelled the development of the research on scientific evaluation. Third, the evaluation on the academic research impact based on social networks transformed the traditional academic evaluation based on citation analysis indicators. The discipline of altmetrics was established (Table 5).

Table 4: Second-stage Evolution in Central Research Topics (Period II: 1995-2005)

\begin{tabular}{|c|c|c|c|c|c|}
\hline Year & Cluster Identifier(Size) & $\begin{array}{l}\text { Proportion } \\
\text { in total size }\end{array}$ & Year & Cluster Identifier(Size) & $\begin{array}{l}\text { Proportion } \\
\text { in total size }\end{array}$ \\
\hline \multirow[t]{2}{*}{1995} & $\begin{array}{l}\text { Technological } \\
\text { innovation }\end{array}$ & $21 \%$ & \multirow[t]{2}{*}{2001} & Academic research & $18 \%$ \\
\hline & Interactive Boolean & $16 \%$ & & Information retrieval & $15 \%$ \\
\hline \multirow{2}{*}{1996} & Technical change & $20 \%$ & \multirow{3}{*}{2002} & Web search engine & $11 \%$ \\
\hline & Online catalog & $15 \%$ & & Knowledge base & $11 \%$ \\
\hline \multirow[t]{2}{*}{1997} & Information retrieval & $15 \%$ & & $\begin{array}{l}\text { Investment appraisal } \\
\text { procedure }\end{array}$ & $10 \%$ \\
\hline & Scientometrics & $15 \%$ & \multirow{3}{*}{2003} & Site interlinking & $11 \%$ \\
\hline \multirow{2}{*}{1998} & Information retrieval & $14 \%$ & & Citation analysis & $10 \%$ \\
\hline & Bibliometric analysis & $13 \%$ & & Scientific literature & $7 \%$ \\
\hline \multirow{3}{*}{1999} & $\begin{array}{l}\text { Strategic } \\
\text { competitiveness }\end{array}$ & $8 \%$ & \multirow{3}{*}{2004} & Web impact factor & $9 \%$ \\
\hline & Corporate technology & $7 \%$ & & Wide web & $9 \%$ \\
\hline & Technology policy & $7 \%$ & & Citation identities & $9 \%$ \\
\hline \multirow[b]{2}{*}{2000} & Technology policy & $20 \%$ & \multirow[b]{2}{*}{2005} & Innovation speed & $16 \%$ \\
\hline & $\begin{array}{l}\text { Complex product } \\
\text { system }\end{array}$ & $15 \%$ & & Research performance & $10 \%$ \\
\hline
\end{tabular}

Note: Proportion in total size means nodes of cited papers (proportion of total size is from citations, and not the number of papers)

The central research topics in scientometric studies changed considerably in 2008. Scientometric indicators became the central research topic and studies were centered on $\mathrm{h}$ index, citation indicator, and crown indicator. The change in central research topics was mainly due to an article by Hirsch (2005), which put forward the idea of $h$-index for the first time. $\mathrm{H}$-index has been the central research topic four times (in 2008, 2009, 2011, and 2015). In particular, h-index accounted for 30 percent of the central research topics in 2008. During this period, the researchers introduced a series of variants of $h$-index, such as g-index, $R$ index, AR-index, and M-index. Besides, research topics such as scientific combination, citation network and knowledge map of literature, triple helix, knowledge base, and twitter index also achieved considerable development in this period and became the central research topics. The integrated online impact indicator (9\%) became the central research topic for the first time in 2010. In 2016, twitter index became the central research topic. 
Altmetrics as an emerging research orientation has received significant attention from scholars and has achieved rapid development since its establishment in 2010. It will continue to be the focus of future research.

Table 5: Third-stage Evolution in Central Research Topics (Period III: 2006-2016)

\begin{tabular}{|c|c|c|c|c|c|}
\hline Year & Cluster Identifier(Size) & $\begin{array}{c}\text { Proportion } \\
\text { in total } \\
\text { size }\end{array}$ & Year & $\begin{array}{c}\text { Cluster } \\
\text { Identifier(Size) }\end{array}$ & $\begin{array}{l}\text { Proportion in } \\
\text { total size }\end{array}$ \\
\hline \multirow{3}{*}{2006} & Firm value & $12 \%$ & \multirow{3}{*}{2012} & Crown indicator & $11 \%$ \\
\hline & Bibliometric analysis & $12 \%$ & & Knowledge base & $9 \%$ \\
\hline & Social science & $11 \%$ & & Citation indicator & $9 \%$ \\
\hline \multirow[b]{2}{*}{2007} & Patent citation & $16 \%$ & \multirow{3}{*}{2013} & Audience factor & $12 \%$ \\
\hline & Information retrieval & $16 \%$ & & $\begin{array}{l}\text { International } \\
\text { mobility }\end{array}$ & $10 \%$ \\
\hline 2008 & h-index & $30 \%$ & & $\begin{array}{l}\text { Scientometric } \\
\text { indicator }\end{array}$ & $9 \%$ \\
\hline \multirow[b]{2}{*}{2009} & h-index & $22 \%$ & \multirow[b]{2}{*}{2014} & Triple helix & $13 \%$ \\
\hline & $\begin{array}{l}\text { International joint } \\
\text { ventures }\end{array}$ & $11 \%$ & & Systems biology & $12 \%$ \\
\hline \multirow{3}{*}{2010} & Bibliometric mapping & $12 \%$ & \multirow{3}{*}{2015} & h-index & $12 \%$ \\
\hline & Academic inventor & $10 \%$ & & Similarity measure & $12 \%$ \\
\hline & $\begin{array}{l}\text { Integrated online } \\
\text { impact indicator }\end{array}$ & $9 \%$ & & Scientific portfolio & $12 \%$ \\
\hline \multirow{3}{*}{2011} & relative indicator & $12 \%$ & \multirow{3}{*}{2016} & Twitter index & $12 \%$ \\
\hline & energy-index & $11 \%$ & & $\begin{array}{l}\text { Quantitative } \\
\text { analysis }\end{array}$ & $10 \%$ \\
\hline & $\mathrm{H}$-index & $10 \%$ & & $\begin{array}{l}\text { Article co citation } \\
\text { network }\end{array}$ & $9 \%$ \\
\hline
\end{tabular}

Note: Proportion in total size means nodes of cited papers (proportion of total size is from citations, and not the number of papers)

According to Kuhn's paradigm theory on scientific revolution, scientometrics is, at present, in an important period of research "revolution" (Kuhn 1962). This revolution includes mainly two aspects. First, more studies are focused on the impact of science on society and a series of new research tools and methods, namely altmetrics, have been playing an increasingly important role in this process. Second, a series of achievements have been produced on the basis of $\mathrm{H}$-index studies (Bornmann 2014). These two changes in scientometric research became the central research topics in 2016 and 2008, respectively. It can be predicted that altmetrics will becomea central research topic within the next few years. According tothe four evolutionary stages of science put forward by Shneider, scientometrics is currently in the third stage, that is, the tools developed by one subject can also be applied to other subjects, or "a Stage III specialty may contribute to a specialty in its own Stage II" (Shneider 2009). 


\section{Evolution of Geographical Research Centres}

This study extracts information on the institutions and countries that produced literature on the central research topics in scientometrics and arranges them according to their size from the highest to the lowest, with the top five being the research centres (including institutions and countries) each year (Table 6 - Table 8). Furthermore, this study conducts visualized analyses of the year-by-year distribution of hot regions of scientometric institutions between 1971 and 2016 using Google Fusion Tables. Significant changes can be found in the distribution of hot regions in the years 1997, 2001, 2004, and 2013. These changes are shown in Figure 2.

Table 6: First-stage Evolution in Geographical Research Centres (1971-1994)

\begin{tabular}{clc}
\hline \hline Year & \multicolumn{1}{c}{ Main Institutions } & Main Countries \\
\hline \multirow{2}{*}{$1971-1993$} & $\begin{array}{l}\text { Hungarian Academy of Sciences, KU Leuven, Leiden } \\
\text { University, University of Sussex, Cornell University }\end{array}$ & $\begin{array}{l}\text { USA, Britain, Hungary, } \\
\text { Canada, Netherlands }\end{array}$ \\
& $\begin{array}{l}\text { Stanford University, University of Maryland, University of } \\
\text { Michigan, University of California, Washington University }\end{array}$ & $\begin{array}{l}\text { USA, France, Canada, } \\
\text { Britain, Germany }\end{array}$ \\
\hline \hline
\end{tabular}

Table 7: Second-stage Evolution in Geographical Research Centres (1995-2005)

\begin{tabular}{|c|c|c|}
\hline Year & Main Institutions & Main Countries \\
\hline 1995 & $\begin{array}{l}\text { University of Maryland, University of California, University } \\
\text { of Massachusetts, University of North Carolina, Florida } \\
\text { State University }\end{array}$ & $\begin{array}{l}\text { USA, Britain, Canada, } \\
\text { France, Netherlands }\end{array}$ \\
\hline 1996 & $\begin{array}{l}\text { University of Sussex, University of California, University of } \\
\text { Michigan, CNR, University of North Texas }\end{array}$ & $\begin{array}{l}\text { USA, Britain, Italy, } \\
\text { Denmark, Germany }\end{array}$ \\
\hline 1997 & $\begin{array}{l}\text { University of Amsterdam, University of North Carolina, } \\
\text { Leiden University, University of North Texas, Rutgers } \\
\text { University }\end{array}$ & $\begin{array}{l}\text { USA, Netherlands, } \\
\text { Britain, Spain, Italy }\end{array}$ \\
\hline 1998 & $\begin{array}{l}\text { Columbia University, New York University, University of } \\
\text { Sussex, University of California, Stockholms University }\end{array}$ & $\begin{array}{l}\text { USA, Britain, } \\
\text { Netherlands, } \\
\text { Canada, Sweden }\end{array}$ \\
\hline 1999 & $\begin{array}{l}\text { University of Reading, Max Planck Society, Schindler } \\
\text { Group, University of Montreal, Stockholms University }\end{array}$ & $\begin{array}{l}\text { Britain, USA, } \\
\text { Germany, Sweden, } \\
\text { Switzerland }\end{array}$ \\
\hline 2000 & $\begin{array}{l}\text { University of Sussex, Maastricht University, India Academy } \\
\text { of sciences, Stanford University, Georgia Institute of } \\
\text { Technology }\end{array}$ & $\begin{array}{l}\text { Britain, USA, } \\
\text { Netherlands, France, } \\
\text { Norway }\end{array}$ \\
\hline 2001 & $\begin{array}{l}\text { Université de Strasbourg, Drexel University, University of } \\
\text { Sussex, Louisiana State University, University of North } \\
\text { Carolina }\end{array}$ & $\begin{array}{l}\text { USA, France, Britain, } \\
\text { Netherlands, } \\
\text { Germany }\end{array}$ \\
\hline 2002 & $\begin{array}{l}\text { Boston University, University of Pennsylvania, McGill } \\
\text { University, University of Sheffield, Leiden University }\end{array}$ & $\begin{array}{l}\text { USA, Britain, } \\
\text { Netherlands, Italy, } \\
\text { Canada }\end{array}$ \\
\hline
\end{tabular}


Hou, J. \& Yang, $X$.

2003

2004

2005
University of Wolverhampton, KU Leuven, University of West Ontario, University of Pittsburgh, Indiana University

University of Wolverhampton, University of Arizona, Drexel University, University of West Ontario, University of Copenhagen

University of North Carolina, Georgia Institute of Technology, University of Nottingham, University of Copenhagen, Max Planck Society
Britain, USA,

Belgium, Netherlands, Canada

USA, Britain, Denmark, Netherlands, Canada

USA, Britain, Netherlands, Germany, Denmark

Table 8: Third-stage Evolution in Geographical Research Centres (2006-2016)

\begin{tabular}{|c|c|c|}
\hline Year & Main Institutions & Main Countries \\
\hline 2006 & $\begin{array}{l}\text { KU Leuven, University of Sussex, Polytechnic University of } \\
\text { Valencia, University of Quebec, University of California }\end{array}$ & $\begin{array}{l}\text { Belgium, USA, } \\
\text { Britain, Spain, China }\end{array}$ \\
\hline 2007 & $\begin{array}{l}\text { University of Pennsylvania, National University of } \\
\text { Singapore, University of Tampere, Rutgers University, } \\
\text { University of Wales }\end{array}$ & $\begin{array}{l}\text { USA, Britain, } \\
\text { Germany, China, } \\
\text { Finland }\end{array}$ \\
\hline 2008 & $\begin{array}{l}\text { University of Amsterdam, Bar-Ilan University, University of } \\
\text { Wolverhampton, KU Leuven, University Hasselt }\end{array}$ & $\begin{array}{l}\text { Belgium, } \\
\text { Netherlands, } \\
\text { Britain, USA, China }\end{array}$ \\
\hline 2009 & $\begin{array}{l}\text { KU Leuven, Hungarian Academy of Sciences, University of } \\
\text { Tokyo, Indiana University, University Hasselt }\end{array}$ & $\begin{array}{l}\text { USA, Belgium, } \\
\text { Britain, China, } \\
\text { Hungary }\end{array}$ \\
\hline 2010 & $\begin{array}{l}\text { Leiden University, University of Amsterdam, Politecnico di } \\
\text { Torino, University of Sussex, University of Pennsylvania }\end{array}$ & $\begin{array}{l}\text { Netherlands, USA, } \\
\text { Italy, Britain, China }\end{array}$ \\
\hline 2011 & $\begin{array}{l}\text { University of Amsterdam, Max Planck Society, Leiden } \\
\text { University, Politecnico di Torino, Zhejiang University }\end{array}$ & $\begin{array}{l}\text { Netherlands, China, } \\
\text { Spain, Italy, USA }\end{array}$ \\
\hline 2012 & $\begin{array}{l}\text { University of Amsterdam, CNR, KU Leuven, CSIR National } \\
\text { Institute of Science Communication and Information } \\
\text { Resources (India), Zhejiang University }\end{array}$ & $\begin{array}{l}\text { Netherlands, USA, } \\
\text { Spain, Italy, China }\end{array}$ \\
\hline 2013 & $\begin{array}{l}\text { CNR, Max Planck Society, University of Amsterdam, } \\
\text { University of Copenhagen, Spanish National Research } \\
\text { Council }\end{array}$ & $\begin{array}{l}\text { Italy, Spain, USA, } \\
\text { China, Germany }\end{array}$ \\
\hline 2014 & $\begin{array}{l}\text { Drexel University, University of Amsterdam, Wuhan } \\
\text { University, Spanish National Research Council, Leiden } \\
\text { University }\end{array}$ & $\begin{array}{l}\text { USA, China, South } \\
\text { Korea, Netherlands, } \\
\text { Spain }\end{array}$ \\
\hline 2015 & $\begin{array}{l}\text { Zhejiang University, National Research Council of Italy, } \\
\text { Spanish National Research Council, Shanghai Jiao Tong } \\
\text { University, Leiden University }\end{array}$ & $\begin{array}{l}\text { USA, China, Spain, } \\
\text { Italy, Germany }\end{array}$ \\
\hline 2016 & $\begin{array}{l}\text { University of Wolverhampton, Max Planck Society, } \\
\text { University of Amsterdam, Beijing Normal University, } \\
\text { University Kassel }\end{array}$ & $\begin{array}{l}\text { Britain, Germany, } \\
\text { Spain, Italy, China }\end{array}$ \\
\hline
\end{tabular}


Overall, the hot regions in scientometrics are gradually migrating from America and Europe to Asia, and America, Europe, and Asia are the three current hot regions (in red) (Figure 2d). The number of scientometrics research institutions is increasing each year and spreading in geography. To begin with, research institutions in the US and Britain increased and spread to neighboring countries and then Asian countries. The hot regions of scientometrics researches in 1997 were mainly located in European countries such as the Netherlands, Britain, Belgium, and Germany, and Northeastern USA in North America (for instance, University of Amsterdam, Drexel University, and Leiden University), with no hot regions in Asia or South America (Figure 2-a). Between 1997 and 2005, the relevant research institutions in North America and Europe grew rapidly and gradually spread to neighboring districts and countries. Italy and France became the hot regions in 2001 (Figure 2-b), and China became a hot region in 2004 and then a centre of research (Figure 2-c). Between 2005 and 2015, the hot regions were still distributed in America, Europe, and Asia; and Spain became a hot region (Figure 2-d). The research institutions in these hot regions included the University of Amsterdam, University of Wolverhampton, KU Leuven, and Leiden University.

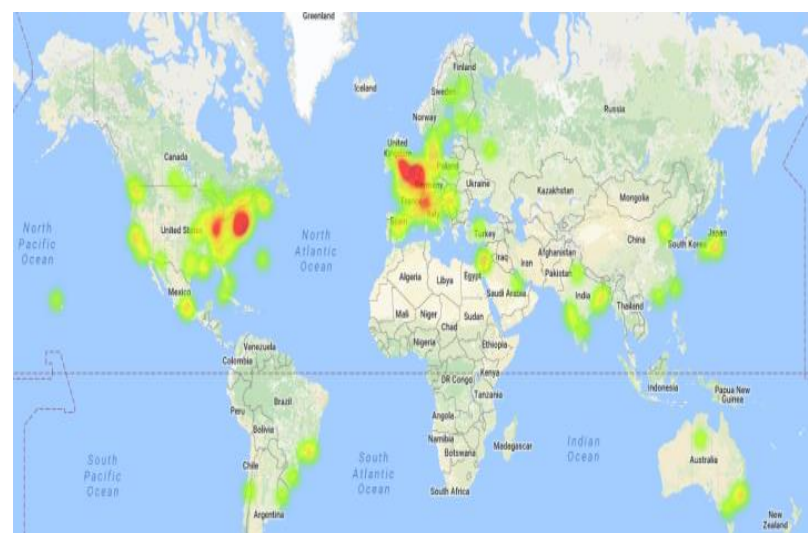

a. In the year 1997

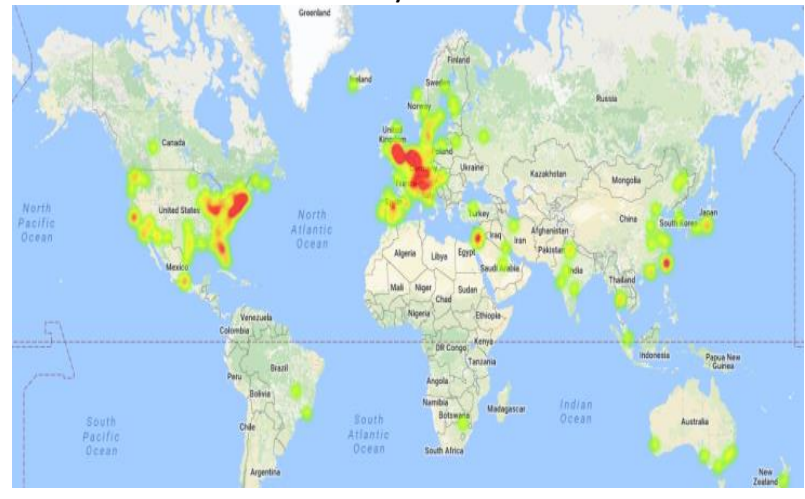

c. In the year 2004

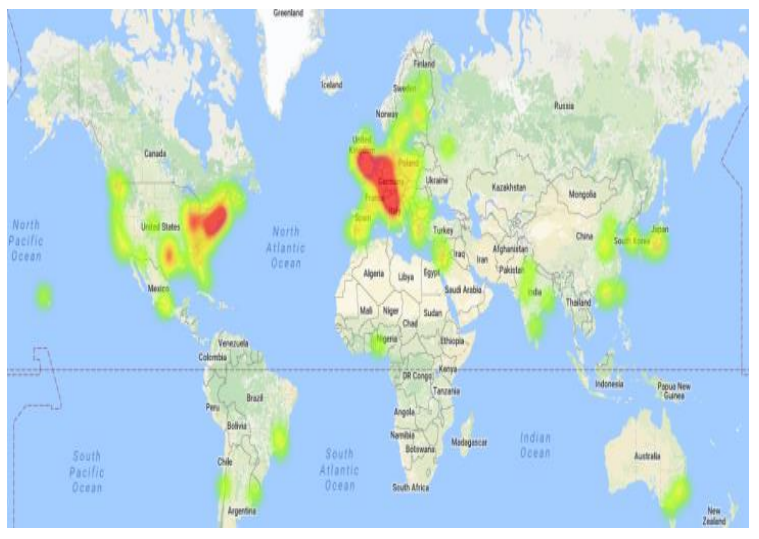

b. In the year 2001

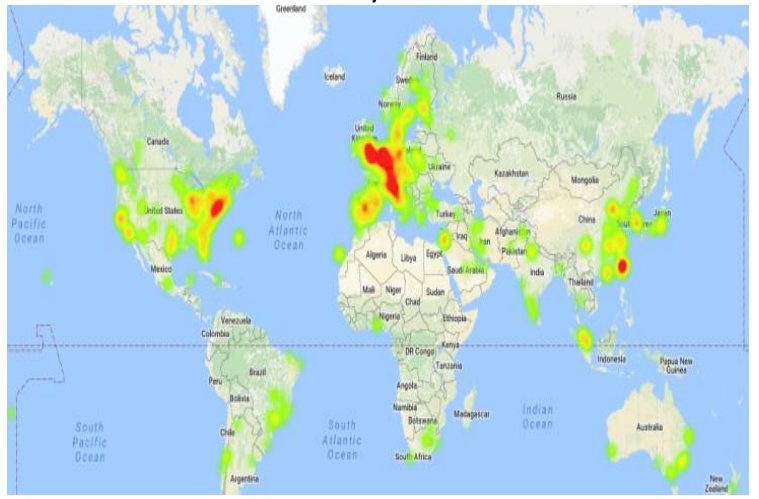

d. In the year 2013

Figure 2: Distribution Map of Relevant Institutions

Overall, the institutions as research centres in Scientometrics experienced great changes every year. From 1971 to 2000, major research institutions were located only in America and Europe. Especially during 1971-1993, European institutions constituted a large part of the major research institutions including Hungarian Academy of Sciences, KU Leuven, Leiden University, University of Sussex, and Cornell University. Between 1994 and 2000, major institutions in America were far more than those in Europe. Major American institutions included University of Maryland, University of California, and University of North Texas. 
During 2000-2016, the major research institutions included University of Wolverhampton, KU Leuven, University of Amsterdam, and Leiden University.

However, an increasingly high number of Asian institutions became the major research institutions such as India Academy of Sciences in 2000 and National University of Singapore in 2007. China ranked among the top five among countries, as the centre of research in scientometrics, between 2006 and 2010, while no Chinese research institution became the research centre institution. However, Zhejiang University, Wuhan University, Shanghai Jiao Tong University, and Beijing Normal University in China became research centres institutions successively since 2011. In addition, some institutions in other Asian countries also became research centres in scientometrics. However, due to the limited number of research institutions, other Asian countries such as India, Singapore, and Japan could not be ranked as research centre countries.

From a geographic perspective, the general tendency was that the research centres in scientometrics migrated from the US, Britain, and Hungary to Italy, the Netherlands, Germany, Belgium, Spain, and China. During 1971-2005, the research centres were dominated by the US and Britain for a long time. Between 1971 and 1993, the countries that were research centres included the US, Britain, Hungary, Canada, and the Netherlands, with the period of scientific prosperity being 23 years. During the period 1994-2005, the research centres included the US, Britain, the Netherlands, Canada, and Germany, with the period of scientific prosperity being 12 years. During 2006-2016, the leading countries among research centres changed from the US and Britain to the Netherlands, the US, and Belgium. Besides, the period of scientific prosperity shortened greatly and the shift of research centres accelerated, showing a high level of activity in scientometric studies. The current countries that are research centres include the Netherlands, the US, Belgium, China, Spain, and Italy (Figure 3 ). In recent years, the ranking of China and Spain rose gradually among the research centres and the institutions in these two countries also became research centres several times. In the near future, China and Spain are very likely to become leading countries in scientometric studies.

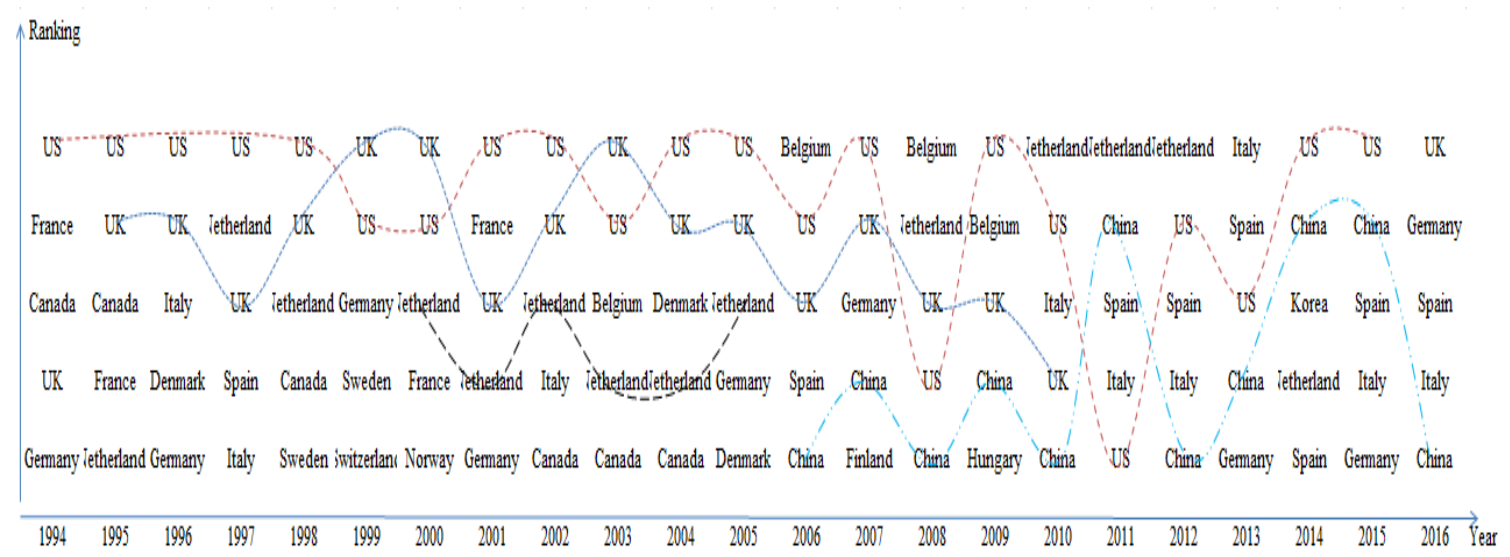

Figure 3: Transfer of Countries that are Research Centres in Scientometrics

A comparison of the central research topics and geographical research centres shows high agreement between the time points of their transfer. The change in research direction on a grand scale occurs in three stages, which happen in the same period as the shift in research centres. However, for specific research directions, this change in topics and geographical 
centres takes place at slightly different times, which means that the geographical evolution of research centres is effected by the temporal evolution of central research topics.

\section{The Relationship between the Country as a Centre of Research and its Academic Influence}

Between 2006 and 2016, the US, the Netherlands, Belgium, China, Spain, and Italy remained centres of research in scientometrics. This study chose six countries, which include the Netherlands, the US, China (including Mainland and Taiwan) and Spain, and conducts comparative analyses of the literature output, citation frequency, and h-index of these countries, which are centres of research, and those of Australia and South Korea, which are not centres of research (Australia and South Korea ranked at the top in the number of published articles in scientometrics among countries which are not centres of research). Between 2000 and 2014, the total output of literature from these six countries accounts for over 60 percent of the total worldwide output of literature in scientometrics every year.

In terms of the output of literature (Figure 4), the output of literature from the US was significantly higher than that of the other five countries during the period 2000-2005. The gap between the output of literature of the Netherlands and that of the other four countries was relatively small during this period. In some cases, the Netherlands was even surpassed by countries that were not centres of research in terms of the output of literature. Between 2005 and 2014, the output of literature from the centres of research grew rapidly and was ahead of the outputs of Australia and South Korea. Among these centres of research, China enjoyed the greatest increase in literature output, surpassed the Netherlands in 2009, and narrowed the gap between itself and the US. However, the Netherlands was the leading country in terms of research centres between 2009 and 2014, while China ranked far behind. Therefore, the rank of a country as a centre of research is not proportional to the output of literature of that country each year.

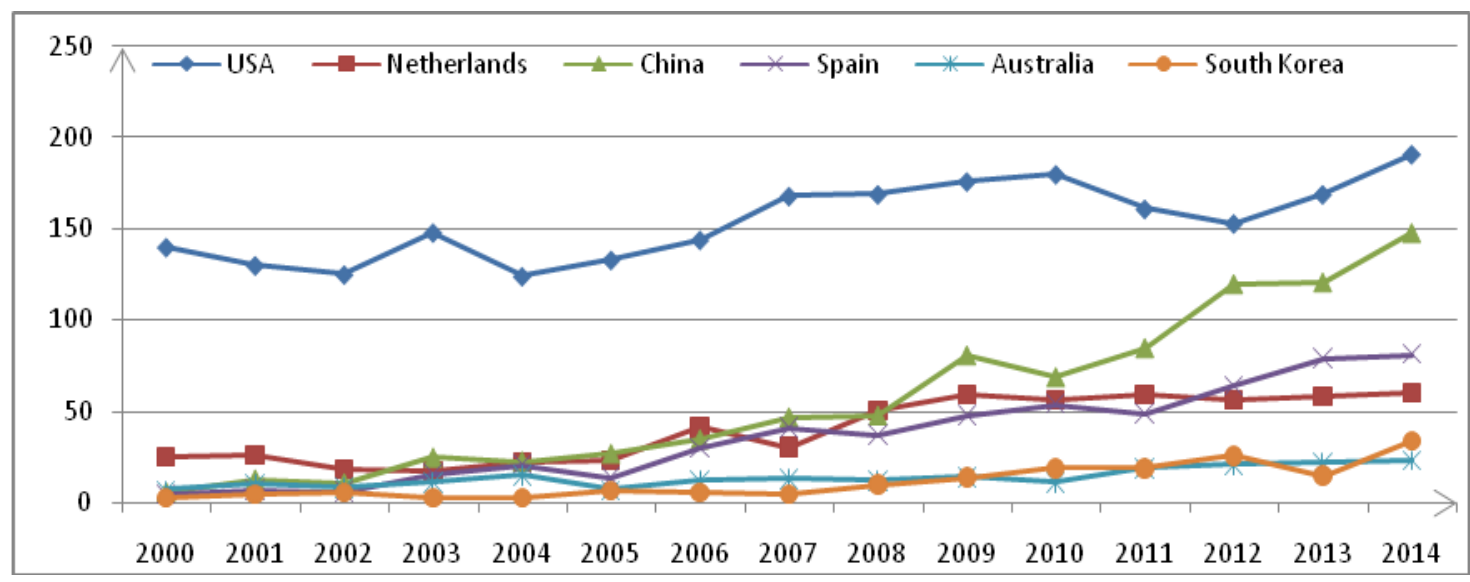

Figure 4: Number of Published Articles from the Six Countries during 2000-2014

In terms of the citation frequency (Figure 5), the total citation frequency of the US fluctuated considerably while those of the other five countries fluctuated less. However, the US was still ranked the first in total citation frequency, due to its huge number of published articles. The gap between the citation frequency of the US and that of the Netherlands was significant between 2000 and 2009. This gap was gradually narrowed between 2010 and 2014, and the Netherlands replaced the US to become the leading country in terms of research centres, even though the number of published articles from the US was three times more than that of Netherlands during this period. This demonstrates the influence of Netherlands at that 
time. The citation frequencies of the US and the Netherlands were higher than those of China and Spain, while the citation frequencies of China and Spain were higher than those of Australia and South Korea. This shows that the influence of the leading countries that are centres of research is greater than that of the other countries, which are centres of research, while the influence of countries that are centres of research but not leading countries is greater than that of countries that are not centres of research.

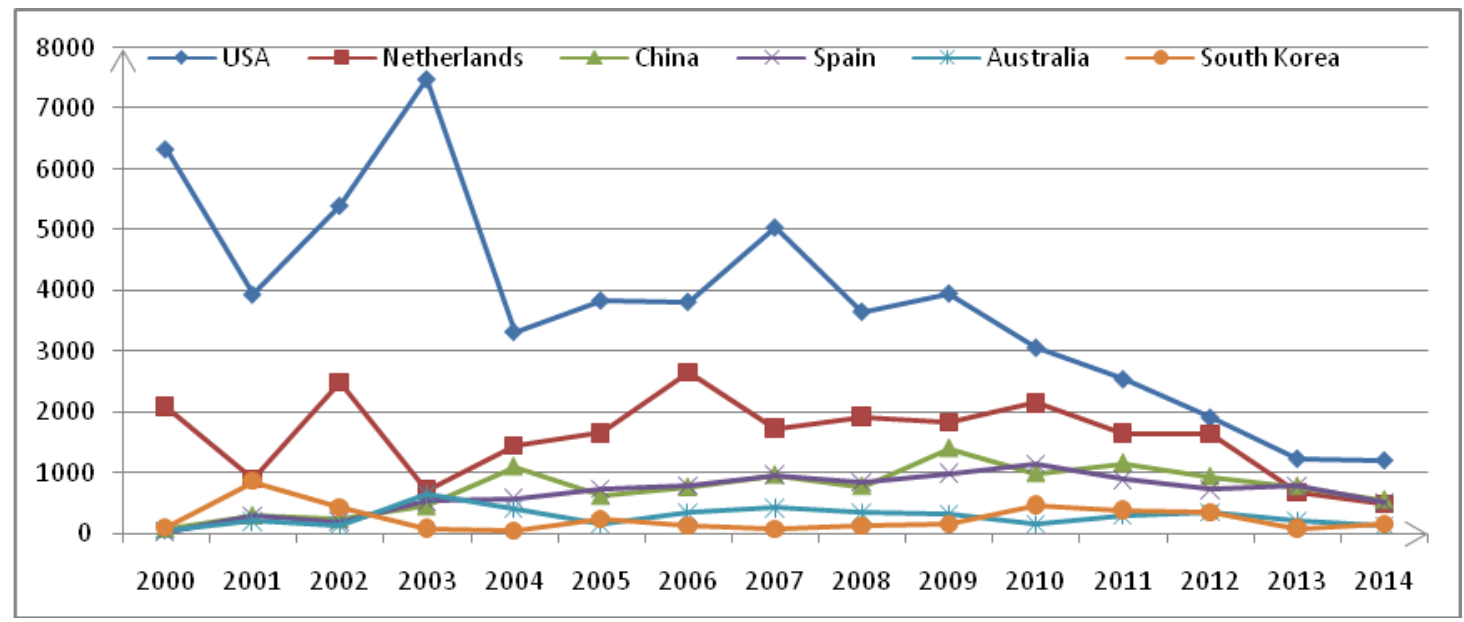

Figure 5: Citation Frequency of Literature from the Six Countries during 2000-2014

In terms of the h-index (Figure 6), the h-indexes of the US and the Netherlands were far above those of the other countries between 2000 and 2005. Between 2005 and 2014, the hindexes of China and Spain rose rapidly, and their gap with the US and the Netherlands narrowed while the gap with Australia and South Korea widened. China and Spain became centres of research during this period, demonstrating that countries as centres of research enjoy great influence. This study compares the change in h-index of the US and the Netherlands between 2010 and 2014. The result shows that the h-index of the Netherlands grew gradually and surpassed that of the US in 2012 for the first time. The Netherlands took the place of the US as the leading centre of research in scientometrics during this period. Overall, the countries that are centres of research are sure to achieve an $\mathrm{h}$-index higher than 10 , in 3 to 5 years after their scientific literature in scientometrics has been published. From the three aspects mentioned above, countries as centres or research may not enjoy high output of literature, but enjoy considerable overall influence.

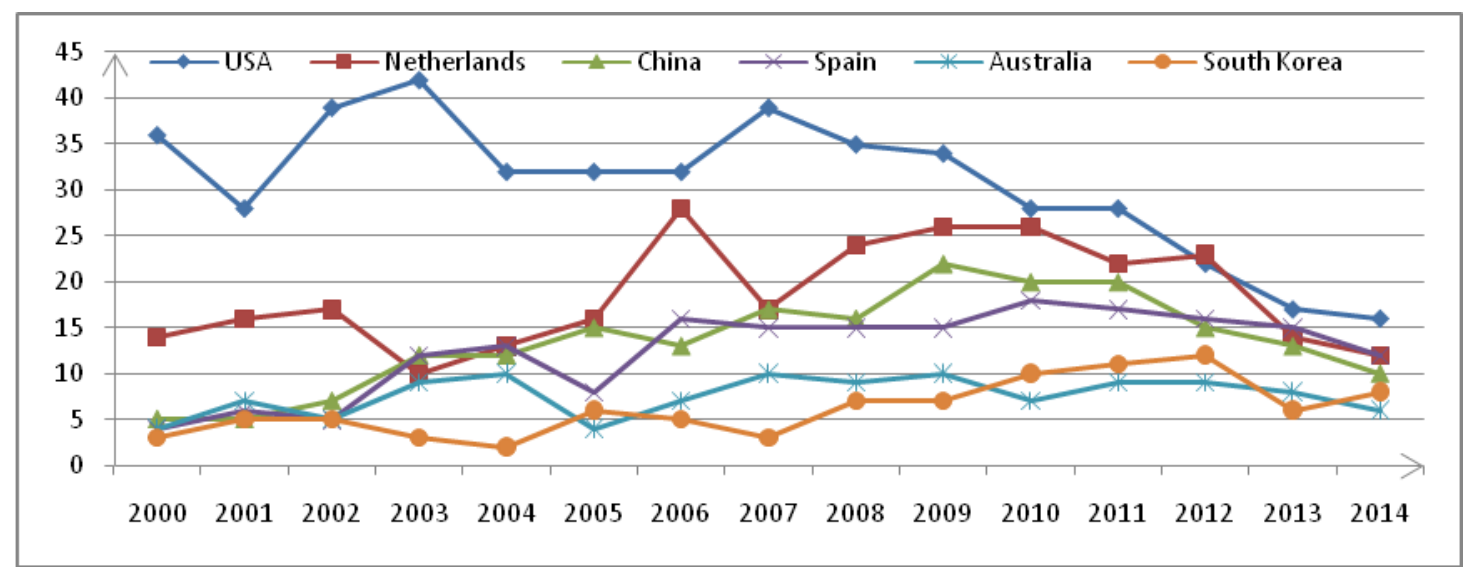

Figure 6: H-index of the Six Countries from 2000 to 2014 


\section{DISCUSSION}

Unlike the traditional method of scientometrics analysis based on knowledge structure in terms of discipline, this study presents a visual analysis of scientometrics studies and extracts the year-by-year central research topics and the institutions and countries that are research centres.

Some interesting results were also revealed in this study. Such as, thorough analysis we found that between 2005 and 2006, the research focus turned to enterprise management application, the pace of innovation, research performance, and corporate value, etc. This is consistent with the findings of Etzkowitz (2005), Leydesdorff (2000), Eun (2006) and Leydesdorff (2010). We also found the studies on scientometric indicators represented by h-index achieved leapfrog development after 2006, This is consistent with the findings of Benevenuto, Laender and Alves (2016). The evaluation on the academic research impact based on social networks transformed the traditional academic evaluation based on citation analysis indicators. This is similar to the results of Bornmann and Haunschild (2016a; 2016b). Research topics such as scientific combination, citation network and knowledge map of literature, triple helix, knowledge base, and twitter index also achieved considerable development, This is consistent with the findings of Haustein et al. (2016), Lahuerta-Otero and Cordero-Gutiérrez (2016) and Laylavi, Rajabifard and Kalantari (2017).

This study has several implications for researchers and practitioners. It provides a reliable historiographical survey of scientometrics studies. The enhanced science mapping procedure introduced in this paper is applicable to the analysis of other fields of interest. Researchers can conduct visualized analysis on various specialties according to their needs and effectively learn the dynamic evolution of these specialties. However, the field of scientometrics represented by four core journals has limitations on data selection. It is better to choose different journals in different periods to define the field of scientometrics and its evolution. CiteSpace can be employed to perform automatic cluster labeling in order to reduce the subjectivity in manual cluster labeling and research topic analysis. However, the subjectivity cannot be completely avoided in choosing central research topics and in defining the period of research prosperity. On the one hand, future studies are expected to improve the methods used in identifying scientometrics journals. On the other hand, future studies should try to minimize the subjectivity in choosing core research topics, and expert opinions should be taken into consideration to achieve accurate and objective research results.

\section{CONCLUSION}

We conduct an in-depth study on the spatial-temporal transfer of scientometrics research topics. The results are as follows:

(a) The temporal evolution of central research topics in scientometrics turn out to have a tendency for accelerated change and diversification. They tended to be polycentric from 2001. There were two central topics during 2001-2007. Since 2008, multiple central research topics in scientometrics have emerged, including scientometrics indicators with h-index, bibliometric mapping based on citation network analysis, altmetrics based on social network, and scientific collaboration with triple helix.

(b) The central research topic is closely related to the migration of the country as centre of research. The temporal evolution of central research topics results in the spatial evolution of geographical research centres. A comparison of the central research 
topics and geographical research centres shows a good agreement between the time points of their transfer.

(c) A country as centre of research has a positive relationship with its academic influence. A country which is a centre of research, enjoys not only a great amount of literature, but also a great academic influence. However, there is no positive correlation between the countries that are centres of research and their literature output. Countries that are not centres of research and those that are centres of research differ greatly in their amount of published articles and influence.

\section{ACKNOWLEDGMENT}

This study was supported by the National Social Science Foundation of China under Grant 17BGL031.

\section{REFERENCES}

Bar-llan, J. 2008. Informetrics at the beginning of the 21st century-A review. Journal of Informetrics, Vol. 2, no.1: 1-52.

Benevenuto, F., Laender, A.H.F. and Alves, B.L. 2016. The H-index paradox: your coauthors have a higher $\mathrm{H}$-index than you do. Scientometrics, Vol. 106, no.1: 469-474.

Bernard, J. D. 1954. Science history. Beijing: Science Press Co. Ltd.

Bernard, J. D. 2010. The social function of science. London: Faber and Faber.2010 edition.

Bornmann, L. 2012. Measuring the societal impact of research. EMBO Reports, Vol. 13, no.8: 673-676.

Bornmann, L. 2015. Alternative metrics in Scientometrics: A meta-analysis of research into three altmetrics. Scientometrics, Vol. 103, no.3: 1123-1144.

Bornmann, L. and Haunschild, R. 2016. T factor: A metric for measuring impact on Twitter. Malaysian Journal of Library \& Information Science, Vol. 21, no.2: 12-20.

Bornmann, L. and Haunschild, R. 2016b. How to normalize Twitter counts? A first attempt based on journals in the Twitter Index. Scientometrics, Vol. 107, no.3: 1405-1422.

Bornmann, L. and Leydesdorff, L. 2014. Scientometrics in a changing research landscape. EMBO reports, Vol. 15, no.12: 1228-1232.

Bradley, E. S., Roberts, D. A., Dennison, P. E. 2011. Google Earth and Google Fusion Tables in support of time-critical collaboration: Mapping the deepwater horizon oil spill with the AVIRIS airborne spectrometer. Earth Science Informatics, Vol. 4, no.4: 169-179.

Chen, C.M. 2017. Science Mapping: A Systematic Review of the Literature. Journal of Data and Information Science, Vol. 2, no.2: 1-40.

Chen, C. M. 2006.CiteSpace II: Detecting and visualizing emerging trends and transient patterns in scientific literature. Journal of the American Society for Information Science and Technology, Vol. 57, no.3: 359 - 377.

Chen, C. M., McCain, K., White, H. and Lin, X. 2002. Mapping scientometrics (1981-2001). In ASIST 2002: Proceedings of the 65th ASIST annual meeting, Vol. 39: 25-34.

Chen, C. M., Ibekwe-SanJuan, F. and Hou, J.H. 2010. The structure and dynamics of cocitation clusters: A multiple-perspective co-citation analysis. Journal of the American Society for Information Science and Technology, Vol. 61, no.7: 1386-1409.

Chen, Y., Borner, K. and Fang, S. 2013. Evolving collaboration networks in scientometrics in 1978-2010: A micro-macro analysis. Scientometrics, Vol. 95, no.3: 1051-1070.

Dampier, W. 1966. A history of science and its relations with philosophy and religion. England: Cambridge University Press. 
Dutt, B., Garg, K. C., and Bali, A. 2003. Scientometrics of the international journal scientometrics. Scientometrics, Vol. 56, no.1: 81-93.

Etzkowitz, H. 2005. The innovating region: toward a theory of knowledge-based regional development. $R$ \& D Management, Vol. 35, no.3: 243-255.

Eun, J. H. 2006. Explaining the "University-run enterprises" in China: A theoretical framework for university-industry relationship in developing countries and its application to China. Research Policy, Vol. 35, no.9: 1329-1346.

Garfield, E. 2009. From the science of science to Scientometrics visualizing the history of science with HistCite software. Journal of Informetrics, Vol. 3, no.3: 173-179.

González-Pereira, B., Guerrero-Bote, V. P., and Moya-Anegón, F. 2010. A new approach to the metric of journals' scientific prestige: The SJR indicator. Journal of Informetrics, Vol. 4, no.3: 379-391.

Guerrero-Bote, V. P. and Moya-Anegón, F. 2012. A further step forward in measuring journals' scientific prestige: The SJR2 indicator. Journal of Informetrics, Vol. 6, no.4: 674688.

Haustein S, Bowman T.D, Holmberg K, Tsou A, Sugimoto C.R, and Lariviere V. 2016. Tweets as impact indicators: Examining the implications of automated "bot" accounts on Twitter. Journal of the Association for Information Science and Technology, Vol. 67, no.1: 232-238.

Hou H., Kretschmer H., and Liu Z. 2008. The structure of scientific collaboration networks in scientometrics. Scientometics, Vol. 75, no.2: 189-202.

Hirsch, J.E. 2005. An index to quantify an individual's scientific research output.Proceedings of the National Academy of Science of the United States of America, Vol. 102, no.46: 16569-16572.

Kuhn, T. S. 1962. The structure of scientific revolutions. Chicago, IL, USA: University of Chicago Press.

Lahuerta-Otero, E., and Cordero-Gutiérrez, R. 2016. Looking for the perfect tweet. The use of data mining techniques to find influencers on Twitter. Computers in Human Behavior, Vol. 64: 575-583.

Laylavi F, Rajabifard, A. and Kalantari, M. 2017. Event relatedness assessment of Twitter messages for emergency response. Information Processing \& Management. Vol. 53, no.1: 266-280.

Leydesdorff, L. 2000. The triple helix: an evolutionary model of innovations. Research Policy, Vol. 29, no.2: 243-255.

Leydesdorff, L. 2010. The triple helix perspective of innovation systems. Technology Analysis \& Strategic Management, Vol. 22, no.7: 789-804.

Leydesdorff, L., and Milojevic, S. 2015. Scientometrics. In M. Lynch (Ed.), International Encyclopedia of Social and Behavioral Sciences. New York: Elsevier.

Liang, L.M., Feng, Y., and Wu, Y.S. 2000. Shifts in the world science centre: Space-time characteristics and disciplinary analysis. Interdisciplinary Science Reviews, Vol. 25, no.3: 227-232.

Marshakova, I. 1973. Bibliographic coupling system based on references. NauchnoTekhnicheskaya Informatsiya, Vol. 2, no.6: 3-8.

Milojevic, S. and Leydesdorff, L. 2013. Information metrics (iMetrics): A research specialty with a socio-cognitive identity? Scientometrics, Vol. 95, no.1: 141-157

Mingers, J., and Leydesdorff, L. 2015. A review of theory and practice in scientometrics. European Journal of Operational Research, Vol. 246, no.1: 1-19.

Moed, H. 2010. Measuring contextual citation impact of scientific journals. Journal of Informetrics, Vol. 4, no.3: 265-277.

Priem, J., and Hemminger, B. M. 2010. Scientometrics 2.0: Toward new metrics of scholarly impact on the social Web. First Monday, Vol. 15, no.7, DOI: 10.5210/fm.v15i7.2874. 
Ravikumar, S., Agrahari, A., Singh, S. N. (2015). Mapping the intellectual structure of scientometrics: a co-word analysis of the journal Scientometrics (2005-2010). Scientometrics, Vol. 102, no.1: 929-955.

Schoepflin, U. and Glänzel, W. 2001. Two decades of "Scientometrics"-An interdisciplinary field represented by its leading journal. Scientometrics, Vol. 50, no.2: 301-312.

Schubert A. (2002). The web of scientometrics: A statistical overview of the frist 50 volumes of the journal Scientometrics. Scientometrics, Vol. 53, no.1: 3-20.

Shneider, A. M. 2009. Four stages of a scientific discipline: four types of scientists. Trends in biochemical sciences, Vol. 34, no.5: 217-223.

Signore, A. 2016. Mapping and sharing agro-biodiversity using Open Data Kit and Google Fusion Tables. Computers and Electronics in Agriculture, no.127: 87-91.

Small, H. 1973. Co-citation in the scientific literature: A new measure of the relationship between two documents. Journal of the American Society for Information Science, Vol. 24, no. 4: 265-269.

Wang, F. F., Qiu, J. P., and Yu, H. Q. 2012. Research on the cross-citation relationship of core authors in scientometrics. Scientometrics, Vol. 91, no.3: 1011-1033.

Wouters, P. and Leydesdorff, L. 1994. Has Price's dream come true: Is scientometrics a hard science? Scientometrics, Vol. 31, no.2: 193-222.

Yuasa, M. 1962. Center of scientific activity: its shift from the 16th to the 20th century. Japanese studies in the history of science, Vol. 1, no.1: 57-75.

Zhao, H.Z. and Jiang, G.H. 1985. Shifting of worlds science center and scientists social ages. Scientometrics, Vol. 8, no.1-2: 59-80.

Zhao, Y. H. and Zhao, R. Y. 2016. An evolutionary analysis of collaboration networks in scientometrics. Scientometrics, Vol. 107, no.2: 759-772. 